\title{
Psychometric Evaluation of the Ostomy Complication Severity Index
}

\author{
Joyce Pittman PhD, RN, ANP-BC, FNP-BC, CWOCN \\ Tamilyn Bakas, PhD, RN, FAHA, FAAN \\ Marsha Ellett, PhD, RN \\ Rebecca Sloan, PhD, RN, ANP-BC \\ Susan M. Rawl, PhD, RN, FAAN
}

Corresponding author:

Joyce Pittman, PhD, RN, ANP-BC, FNP-BC, CWOCN

Indiana University Health

Indiana University School of Nursing

1704 N. Capitol Ave., Room B149

Indianapolis, IN 46202

Fax 317-962-9762

Phone 317-962-0810

jpittma3@iuhealth.org

This study was supported through funding from Indiana University School of Nursing Research Grant.

I would like to gratefully acknowledge the support of the Indiana University Health Wound/Ostomy nurses that assisted in this research endeavor: Tanya Clary, RN, CNS, CWOCN and Kathleen Wilson, RN, CWOCN.

This is the authors' accepted manuscript of the article, published in final form:

Pittman J, Bakas T, Ellett M, Sloan R, Rawl SM. Psychometric Evaluation of the Ostomy Complication Severity Index: Journal of Wound, Ostomy and Continence Nursing. 2014;41(2):147-57. http://dx.doi.org/10.1097/WON.0000000000000008 


\begin{abstract}
Background: Almost one million individuals are estimated to be currently living with an ostomy in North America, and more than 120,000 new ostomies are created annually in the United States and Canada. ${ }^{1-3}$ Although this surgery saves lives, up to $80 \%$ of patients experience ostomy complications. $^{4-7}$ To reduce these complications and their negative impact on patients' lives, we must expand our knowledge of both their incidence and severity. However, no available instruments have sufficient evidence of reliability and validity to measure ostomy complications. In addition, few studies have been conducted using a conceptual framework to examine ostomy complications.
\end{abstract}

Purpose: The purpose of this study was to evaluate the psychometric properties of a new instrument to measure incidence and severity of ostomy complications early in the postoperative period. We developed an evidence-based conceptual model to guide development and evaluation of this new instrument, the Pittman Ostomy Complication Severity Index (OCSI). This article will report on the development and psychometric testing of the OCSI.

Method: Psychometric testing of the OCSI was, conducted with a convenience sample of 71 participants from three acute care settings within a large healthcare system in the Midwestern United States. Descriptive analyses, content validity indices, inter-rater reliability testing, and construct validity testing were employed.

Results: Of the 71 participants, most were men (52\%), white (96\%), and married or partnered (55\%), and the mean age was 57 years. Fifty-two (84\%) participants experienced at least one ostomy complication in the 60-day post-operative period. Common complications included: leakage (60\%), peristomal irritant dermatitis (50\%), stomal pain (42\%), retraction (39\%), and 
stomal bleeding (32\%). The OCSI demonstrated acceptable evidence of content validity (CVI= 0.9 ) and inter-rater reliability for individual items $(k=.71-1.0)$, as well as almost perfect agreement for total scores among raters (ICC .991, $p \leq .001$ ). Construct validity of the OCSI was supported by significant correlations among variables in the conceptual model (complications, risk factors, stoma care self-efficacy, and ostomy adjustment).

Conclusion: The OCSI has evidence of reliability and validity, and it can be used to assess incidence and severity of ostomy complications in the early postoperative period. The OCSI is brief, easy to use, and clinically practical, and it can be used to a) identify priority areas for nursing intervention related to the ostomy, b) determine appropriate interventions to prevent or treat complications, and c) evaluate the effects of nursing interventions designed to improve outcomes for patients with ostomies.

Key Words: Ostomy complications, psychometric properties, instrument, risk factors, selfefficacy, ostomy adjustment 


\section{Introduction}

Almost one million individuals are estimated to be currently living with an ostomy in North America, and more than 120,000 new ostomies are created annually in the United States and Canada. ${ }^{1-3}$ Although this surgery saves lives, up to $80 \%$ of patients experience ostomy complications $^{4-7}$ that affect them both physically and psychologically. Physically, patients experience peristomal irritant dermatitis, stoma pain, stomal bleeding, stoma necrosis, mucocutaneous separation, herniation, infection, and stoma retraction. ${ }^{4,6,8}$ Psychologically, adjustment to living with an ostomy can be difficult. Not only does the individual have to cope with a serious and often life-threatening diagnosis, but placement of an ostomy requires significant changes to his or her lifestyle. This population is at risk for psychological and social difficulties that affect long-term adjustment. People with ostomies face difficulties adjusting to and coping with their ostomy, social isolation, occupational changes, and challenges in daily living. ${ }^{9-11}$

Adjustment to living with an ostomy becomes more difficult in the presence of complications. Complications require complex ostomy management techniques and additional use of costly ostomy equipment and supplies, and they can disrupt daily, occupational, social, and physical activities. Improvements have occurred in the management of an ostomy, including advanced surgical techniques/procedures and innovative new ostomy equipment, yet complications continue to commonly occur.

A reliable and valid instrument to measure ostomy complications is needed for both researchers and clinicians in order to collect accurate and objective data. At the time of this study, there were no relevant instruments that could be used to measure both incidence and 
severity of ostomy complications. Therefore, the purpose of this study was to evaluate the psychometric properties of a new instrument, the Ostomy Complication Severity Index (OCSI), designed to measure incidence and severity of ostomy complications that develop early in the postoperative period. We constructed an evidence-based conceptual model to guide the development of this new instrument and this study.

Specific research questions and hypotheses tested were:

1. Does the Pittman Ostomy Complication Severity Index (OCSI) demonstrate acceptable content validity, inter-rater reliability, and construct validity?

Hypothesis 1a. The Ostomy Complication Severity Index will demonstrate acceptable content validity as evidenced by expert reviewer ratings of clarity, comprehensiveness, and appropriateness as well as content validity indices of at least 0.80 .

Hypothesis 1b. The OCSI will demonstrate acceptable inter-rater reliability with a Cohen's coefficient kappa greater than or equal to $0.60 .{ }^{12}$ Hypothesis 1c. Construct validity will be supported by significant relationships among the following variables in the Pittman Ostomy Complication Conceptual Model: ostomy complication risk factors, individual ostomy complications, and total Ostomy Complication Severity Index scores.

Hypothesis 1d. Construct validity will also be supported by significant relationships among the following variables in the conceptual model: Ostomy Complication Severity Index (OCSI) scores, Stoma Care Self-Efficacy scores, and Ostomy Adjustment scores. 
2. What are the incidence and severity of ostomy complications 60 days post-operatively among adult patients who have had fecal ostomy surgery in a large Midwestern health system?

\section{Conceptual Model}

Development and psychometric testing of the OCSI were based on the Ostomy Complication Conceptual Model developed specifically for this study. As shown in Figure 1, the model illustrates the relationships among antecedents (intrinsic and extrinsic risk factors), mediator (stoma care self-efficacy), and outcomes (early ostomy complications and ostomy adjustment).

\section{Methods}

Development of the Ostomy Complication Severity Index (OCSI)

DeVellis' step-wise approach for developing instruments was rigorously followed to create the OCSI. The authors identified the construct to be measured, chose items that reflected the instrument's purpose, determined the format for measurement, and obtained expert review of the items. $^{13}$

OCSI items were generated from an extensive review of research and clinical literature and from clinical expertise. The OCSI consisted of nine items from $0-3$, with 0 meaning the complication was not present and 3 meaning it was extremely severe. The complications addressed by the items were, respectively, leakage, peristomal irritant dermatitis, pain, bleeding, stomal necrosis, stomal stenosis, retraction, mucocutaneous separation, and hyperplasia. The OCSI format includes Likert-like scale with individual item scores and a total score computed by summing the individual items. The minimum possible score is 0 and the maximum total score 
possible is 27. Higher scores on the OCSI item or total score indicate more severe ostomy complication(s).

Study Procedures

Phase 1: To establish content validity of the instrument, an expert review was conducted as recommended by DeVellis and described further by Pittman and Bakas. ${ }^{14}$ A panel of 10 Wound, Ostomy, Continence (WOC) nurse experts was recruited from across the United States to participate in a survey to establish the content validity of the instrument. Three experts were doctorally prepared, six were master's-prepared advanced practice nurses, and all were nationally recognized experts in the area of WOC nursing. Each content expert was mailed a packet of information that included the purpose of the survey, conceptual definitions of constructs being measured, and instructions for completing the survey. The content validity survey was developed based on recommendations of Wynd, Lynn, and Sacks. ${ }^{12,15,16}$ Each expert was given specific instructions by which to evaluate the relevance of each of the nine individual items. In addition to item relevance, experts evaluated clarity, comprehensiveness, and appropriateness of each item. The item ratings were on a 4-point ordinal scale with the exception of comprehensiveness, which was on a 2-point nominal scale.

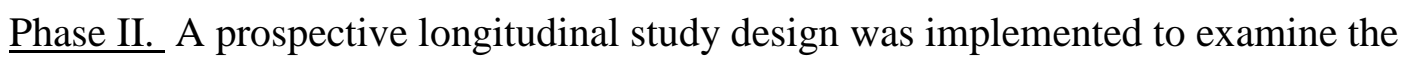
psychometric properties of the new measure. Following approval from university and hospital institutional review boards, a convenience sample of 71 adult patients who had undergone surgery to create a new fecal ostomy, either colostomy or ileostomy, was recruited from three hospital sites within a single healthcare system in the Midwest United States: a 750-bed Level I Trauma Center, a 350-bed university academic teaching hospital, and a 189-bed community hospital. Each of these acute care settings has one or more certified WOC nurses. Eligible 
patients who were undergoing ostomy surgery were identified by a WOC nurse and/or physician in each facility. Potential subjects were informed of the opportunity to participate in the study while receiving standard inpatient care from a WOC nurse. To be eligible for this study, patients had to be: a) 18 years of age or older; b) undergoing surgery for creation of a fecal ostomy during their hospital stay; c) willing and able to return for a post-operative follow-up visit; and d) able to speak and read English. Patients were excluded from participation if they had any diagnosis indicating cognitive impairment or if they were unable to participate in the consent process.

Data Collection. Baseline data were collected prior to discharge (typically five to seven days post-operatively), and follow-up data were collected between 30 and 60 days postoperatively. Data were collected through self-administered surveys, medical review, and direct observation by trained, expert WOC nurses. Table 1 shows measures that were administered at each time point and data sources.

Measures

Demographic information and medical history were collected using a self- administered patient information survey. Stoma care self-efficacy was measured using the Stoma Care SelfEfficacy Scale, a well-established instrument developed by Bekkers and colleagues (13 items, Cronbach alpha $=0.94) .{ }^{17}$ In our study, stoma care self-efficacy was measured at two points in time: baseline and follow-up. The patient or the caregiver, whichever person performed stoma care, completed the instrument. The Cronbach alpha for the scale was 0.96 in this study.

Ostomy adjustment was measured using the Ostomy Adjustment Inventory-23 (OAI-23), developed by Simmons and colleagues to measure social and psychological adjustment of patients with a fecal ostomy. ${ }^{18}$ OAI-23 is a 23 -item, multidimensional, self-report instrument 
that consists of four subscales: acceptance, self-esteem, social engagement, and anger. ${ }^{19}$ Evidence of validity was established in a large sample of 570 British participants with an ostomy. Cronbach alpha was 0.93 for the overall inventory. Test-retest reliability was found to be $0.83 .{ }^{19}$ In our study, the OAI-23 was completed at follow-up and had a Cronbach alpha of 0.91 .

\section{Statistical Analyses}

A primary aim of this study was to determine the psychometric properties of the OCSI. Content validity was examined by calculating the content validity index (CVI). The CVI, an objective method for quantitatively assessing content validity, is calculated based on expert ratings of item relevance, clarity, comprehensiveness, and appropriateness. ${ }^{12}$ A CVI of 0.80 or higher is considered acceptable. ${ }^{20}$ Individual item CVIs were computed by determining the number of items considered to be relevant (rated 3 or 4) by the experts divided by the total number of experts. ${ }^{20}$ The total scale CVI is defined as the "proportion of items on an instrument that achieved a rating of 3 or 4 by all the content experts." ${ }^{20}$ In this study, the total OCSI CVI was calculated by summing the individual CVI scores and dividing by the number of items. ${ }^{16,20}$

Inter-rater reliability was examined by having a second trained WOC nurse, in addition to the principal investigator (who is a certified WOC nurse), independently complete the instrument with a random sample of participants $(n=6)$. Training included content of the instrument, use of the instrument, and applying the scoring rules. Cohen's coefficient kappa was computed to estimate inter-rater reliability. ${ }^{21}$ In addition, the intra-class correlation coefficient was used to assess the strength of agreement between the raters for the OCSI total score using the metric defined by Landis and Koch (1977) in which 0-0.20 = slight agreement; 0.21-0.40= 
fair agreement; 0.41-0.60 = moderate agreement; 0.61-0.80 = substantial agreement; and 0.81$1.0=$ almost perfect agreement. $^{22}$

To assess construct validity of the OCSI, relationships among variables depicted in the Ostomy Complication Conceptual Model were examined. Specifically, relationships between ostomy risk factors (demographic, environmental, and clinical) and ostomy complications were examined. In addition, relationships among stoma care self-efficacy, ostomy adjustment, and ostomy complications were examined. Frequencies were used to examine all patient demographics. .Continuous variables were summarized using means and standard deviations and were compared using analysis of variance (ANOVA). Categorical variables were summarized using frequencies and percentages and were compared using chi-square tests. Correlations among variables were examined and multiple regression analysis was conducted to examine predictors of OCSI total scores. Analyses were performed using SPSS version 19 statistical software.

Results

A sample of 71 adult participants provided baseline data, and 58 participants were retained for follow-up. Thirteen (18\%) were lost to follow-up: Two did not attend their followup appointments, two expired, and nine did not return repeated phone calls to schedule the follow-up visit.

The sample was predominantly white (96\%) with nearly equal numbers of men (52\%) and women (48\%), and more than half (55\%) were married or partnered. More than half had a college education (57\%), 30\% were employed, and 25\% described their financial situation as insufficient to make ends meet. Approximately one third (34\%) of participants required ostomy 
surgery due to colorectal cancer, $21 \%$ to treat inflammatory bowel disease, and $44 \%$ as a result of trauma or other emergent conditions. ${ }^{5}$

\section{Research Question 1: Does the Pittman Ostomy Complication Severity Index (OCSI) demonstrate acceptable content validity, inter-rater reliability and construct validity?}

To test Hypothesis 1a (content validity), experts reviewed the OSCI and content validity was examined. As shown in Table 2, the mean rating for clarity was 3 or above (out of 4 ) for eight of the nine items. The average comprehensiveness rating was 1.8 (out of 2) or higher for all items. Eight of the nine items’ mean rating for appropriateness was 3 (out of 4) or higher. One item (stomal bleeding) was rated lower on clarity (2.4) and appropriateness (2.5) by the experts and, therefore, was revised accordingly. Two types of CVI scores were calculated: 1) content validity of individual items and 2) content validity of the overall scale. All individual item CVI scores were acceptable, ranging from .88 to 1.0. The total OCSI CVI score was 0.91,

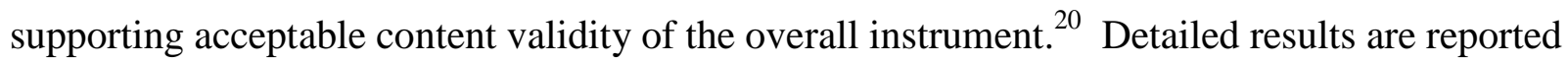
in Table 3. In summary, the results demonstrated acceptable content validity for the OCSI.

To test Hypothesis 1b (Inter-rater reliability), OCSI scoring was compared between two experts on a random sample of participants $(n=6)$. As shown in Table 4, all individual items had a Cohen's coefficient kappa of 0.71 to 1.0. The total score of the OCSI had a Pearson's coefficient of $0.999(p \leq 0.001)$ and an intra-class correlation coefficient of $0.991(p \leq 0.001)$. The OCSI demonstrated acceptable inter-rater reliability on individual items and the total score $^{23}$.

To test Hypothesis 1c (construct validity), relationships among ostomy complications and demographic characteristics were examined (gender, education, employment, marital status, race, and comorbidities). Only female gender was associated with the most severe ostomy 
complications ratings, specifically, for leakage ( $r=0.324, p=0.05)$, pain $(r=0.269, p=0.05)$ and total OCSI scores $(r=0.320, p=0.05)$. Women had significantly higher mean ostomy complication scores than men $(p=0.02)$.

Participants whose stoma site had not been marked pre-operatively by the WOC nurse had more severe retraction $(r=0.32, p=0.01)$ and mucocutaneous separation $(r=0.30, p=0.05)$. BMI was positively correlated with leakage $(r=0.36, p=.01)$, retraction $(r=0.28, p=0.05)$, mucocutaneous separation $(r=0.26, p=.05)$, and ostomy complication total score $(r=0.32, p=$ 0.05). Participants with higher BMIs had more severe leakage, retraction, mucocutaneous separation, and higher ostomy complication severity scores.

Type of ostomy was correlated with leakage $(r=0.31, p=0.05)$ and peristomal irritant dermatitis ( $r=0.26, p=0.05)$; participants with an ileostomy had higher severity scores on these two complications. Stoma/abdomen characteristics were significantly correlated with pain $(r=0.30, p=0.05)$, bleeding $(r=0.28, p=0.05)$, stomal necrosis $(r=0.28, p=0.05)$, retraction $(r=$ 0.57, $p=0.01)$, mucocutaneous separation $(r=0.30, p=0.05)$, and OCSI total score $(r=0.43, p=$ 0.01). Participants with flatter stomas and problematic skin folds/creases had more severe pain, bleeding, stoma necrosis, retraction, mucocutaneous separation, and higher overall ostomy complication scores.

To test construct validity of the OCSI further, relationships among individual risk factors and OCSI total scores using univariate and multivariate regression analyses were conducted (see Table 6). Univariate regression analysis identified two risk factors that were significantly associated with the development and severity of ostomy complications, stoma/abdomen characteristics $(p \leq 0.001)$ and BMI $(p \leq 0.001)$. When all risk factors were entered into the multivariate model, stoma/abdomen characteristics $(p=0.007)$ and BMI $(p=0.002)$ remained 
independent predictors of total ostomy complication scores. These important results indicated that having flatter stomas and/or problematic skin folds at baseline predicted ostomy complication scores at follow-up and that higher BMI was related to higher ostomy complication scores at follow-up. Older age $(p=0.053)$ and needing more assistance with ADL functions ( $p=$ 0.057) at baseline approached significance as predictors of ostomy complications.

To test Hypothesis 1d (construct validity), relationships among Ostomy Complication Severity Index scores, Stoma Care Self-Efficacy scores, and Ostomy Adjustment Inventory-23 scores were examined. Stoma Care Self-Efficacy scores at follow-up were negatively associated with ostomy complication severity scores $(r=-0.300, p=0.05)$. These findings indicate that patients with lower stoma care self-efficacy at follow-up. had higher incidence and severity of ostomy complications, meaning the less confident the participant was in their stoma care, the more ostomy complications that they had.

Stoma Care Self-Efficacy scores at baseline $(r=0.402, p=0.002)$ and at follow-up $(r=$ 0.599, $(p \leq 0.001)$ were positively associated with Ostomy Adjustment scores. Participants who were more confident in caring for their stoma, both at baseline and at follow-up, had a higher ostomy adjustment score, indicating better adjustment.

A significant negative correlation of $r=-0.27(p=0.04)$ was observed between total scores on the OCSI and the Ostomy Adjustment Inventory-23. These results indicate that participants who had a higher incidence of or more severe ostomy complications had more difficulty adjusting to having an ostomy.

In summary, strong evidence of construct validity for the Ostomy Complication Severity Index was identified. Relationships among ostomy complications, risk factors, stoma care selfefficacy, and ostomy adjustment were confirmed. 


\section{Research Question 2: What is the incidence and severity of ostomy complications post- operatively, among adult patients who have fecal ostomy surgery in a large Midwestern health system?}

The incidence and severity of each ostomy complication are presented in Table 7. Results showed that $84 \%$ of participants had at least one ostomy complication after surgery. Almost 60\% reported leakage of their pouching system at follow-up. Thirty-one (50\%) participants reported having, or were observed to have, peristomal irritant dermatitis at followup. Twenty-six (42\%) participants reported having stoma pain. At follow-up, 39 (62\%) participants had a stoma that was above skin level versus 24 (39\%) who had stomal retraction or a stoma that was at skin level or below. Eight (13\%) participants had mucocutaneous separation.

\section{Discussion}

This study generated important new knowledge regarding the reliability and validity of a new instrument to measure incidence and severity of ostomy complications. The OSCI demonstrated acceptable content validity $(\mathrm{CVI}=0.9)$. Expert ratings provided evidence of content validity by evaluating each item as clear, comprehensive, and appropriate. The OCSI demonstrated acceptable inter-rater reliability for each of the nine items $(k=0.71-1.0)$ and excellent correlation of total OCSI scores between raters $(r=0.999, p \leq 0.001)$.

Theoretical relationships among ostomy complications, important individual risk factors, stoma care self-efficacy, and ostomy adjustment provided support for the construct validity of the OCSI. Gender, ostomy type, stoma/abdomen characteristics, BMI, and absence of stoma site marking by the WOC nurse were risk factors associated with the incidence and severity of ostomy complications in expected directions. 
Three environmental factors examined as potential risk factors for complications were stoma site marking, pre-operative education, and post-operative education. Of these WOC nursing interventions, only the absence of stoma site marking was associated with greater severity of ostomy complications, specifically, stomal retraction $(r=0.32, p=0.01)$ and mucocutaneous separation $(r=0.30, p=0.05)$. These findings are consistent with prior studies reporting that patients who had their stoma site marked by the WOC nurse had fewer ostomy complications. ${ }^{8,9,24,25}$ The Wound, Ostomy and Continence Nurses (WOCN) Society's best practice guidelines recommend stoma site marking pre-operatively to reduce the incidence of complications and improve self-care. ${ }^{26}$ In addition, a joint position statement, developed and published by the American Society of Colorectal Surgeons and the WOCN Society (2007), recommended that all patients undergoing ostomy surgery have their stoma site marked by a colorectal surgeon or ostomy nurse. ${ }^{27}$ The results of this study support these recommendations.

This study contributes valuable new information regarding the incidence and severity of fecal ostomy complications in the early post-operative period. Fifty-two (84\%) participants had developed at least one ostomy complication at follow-up, consistent with other studies showing that ostomy complications are common. ${ }^{4}$ Leakage was the most commonly occurring complication with almost $60 \%$ of the participants experiencing this problem. Peristomal irritant dermatitis was the next most commonly occurring complication with a rate of $50 \%$, consistent with other studies reporting peristomal irritant dermatitis rates of $55 \%{ }^{6}$

An important and unique strength of this study was the measurement of both the incidence and severity of ostomy complications. This important information is not found elsewhere in the literature. For example, $11 \%$ of the participants in this study experienced leakage more than once a day and $20 \%$ had moderate to severe peristomal irritant dermatitis. In 
practical terms, this means that $20 \%$ of the participants had not only a rash and irritation around their stoma, but also loss of epithelial tissue similar to a second degree burn. Almost $10 \%$ of study participants rated their stomal pain as 7 or greater. Thirty-nine percent had a stoma that was at skin level or below, which often leads to leakage and peristomal irritant dermatitis. The majority of those with stomal bleeding had superficial bleeding, but $2 \%$ had stomal bleeding that required medical intervention (sutures or transfusion). No other studies were found that reported ostomy complication severity in the detail provided by using the OCSI.

Two other instruments that measure physiological ostomy complications have recently been published; however, neither of them measures incidence and severity as does the OCSI. A study in Italy led to the development of an instrument designed to measure skin injury around the stoma but did not assess other stomal complications such as mucocutaneous separation, retraction, stomal stenosis, stomal necrosis, pain, or bleeding. ${ }^{28}$ Kalashnikova et al. ${ }^{29}$ recently reported a systematic method for diagnosing and selecting treatment options for ostomy complications. These investigators developed an algorithm to facilitate a uniform approach to diagnosing and treating ostomy complications. However, their algorithm has yet to be validated. $^{29}$

Strengths and Limitations

A major strength of this study was the use of the Ostomy Complication Conceptual Model as a guiding framework for identifying specific risk factors, ostomy complications, selfefficacy, and ostomy adjustment. Application of conceptual models in ostomy research has been limited, and there are variations in study design, inconsistent definitions and terminology, and few measures with evidence of reliability and validity for data collection. As a result, comparing research findings across studies is difficult. The use of a conceptual model informs the design, 
variables to be measured, and hypotheses to be tested. The conceptual model guides the choice of empirical indicators. ${ }^{30}$ This development of an evidence-based conceptual model provided a structured and systematic approach for examining ostomy complications and the risk factors that may influence their development. Another major strength is that the use of this new instrument measures not only incidence but severity of the ostomy complication. No other instruments were identified that enable the measurement of both of these constructs.

Several limitations should be noted when interpreting the results of this study. One limitation was the small sample size used to examine inter-rater reliability. At the onset of the study, the goal was to collect inter-rater reliability data on one third of the participants. Unfortunately, due to unforeseen circumstances this was not feasible and inter-rater reliability was evaluated using data from six participants collected by two raters. Further reliability testing is recommended. A second limitation is that results may have limited generalizability and be applicable only to the early post-operative period and to patients in similar types of settings. Further testing of the OCSI is recommended to examine its utility for measuring ostomy complications that develop later in the post-operative period. In addition, the OCSI should be tested further with diverse patients across a variety of health care settings.

\section{Conclusion}

As the momentum for evidence-based practice accelerates, the need for standardized language and validated tools to measure outcomes of ostomy care becomes urgent. ${ }^{31}$ This study's results support the reliability and validity of a new instrument to measure incidence and severity of ostomy complications. The OCSI can be used to identify not only the presence of ostomy complications, but also their severity. The instrument is brief, easy to use, and clinically practical, and it serves as an additional resource for nurse researchers and busy practitioners. 
Ostomy complications negatively affect quality of life for individuals living with an ostomy, often resulting in physical and psychosocial limitations for these individuals and their families. ${ }^{9}$ Not only do persons with an ostomy have to cope with a serious and often lifethreatening diagnosis, but the placement of an ostomy requires significant changes to their lifestyle. This study contributes new scientific knowledge regarding incidence and severity of ostomy complications and relationships among risk factors, ostomy complications, stoma care self-efficacy, and ostomy adjustment. The findings provide a foundation upon which to build future research and develop interventions to improve care and enhance quality of life for individuals living with an ostomy. 


\section{References}

1. Kelman G, Minkler P. An investigation of quality of life and self-esteem among individuals with ostomies. J Enterostomal Ther. Jan-Feb 1989;16(1):4-11.

2. Turnbull G. The Ostomy Files: Ostomy Statistics: The \$64,000 Question. Ostomy Wound Manage. 2003;49(6):22-23. http://www.o-wm.com/article/1756. Accessed June 21, 2007.

3. United Ostomy Associations of America. 2012. http://www.ostomy.org/ Accessed 10/8/2012.

4. Ratliff C, Scarano, K., Donovan, A. Descriptive study of peristomal complications. Journal of Wound, Ostomy, Continence Nursing. January/February 2005 2005;32(1):33-37.

5. Pittman J, \& Rawl, S. . Ostomy complications and associated risk factors: Development and testing of two instruments.: Indiana University School of Nursing; 2011.

6. Colwell J, Goldberg, M., Carmel, J. The state of the standard diversion. Journal of Wound, Ostomy, Continence Nursing. 2001;28:6-17.

7. Persson E, Gustavsson, B., Hellstrom, A., Lappas, G., Hulten, L. Ostomy patients' perceptions of quality of care. Journal of Advanced Nursing. 2005;49(1):51-58.

8. Park J, Del Pino, A., Orsay, C., Nelson, R., Pearl, R., Cintron, J., Abcarian, H. Stoma Complications. Dis Colon Rectum. December 1999;42(12):1575-1580.

9. $\quad$ Pittman J, Rawl, S. M., Schmidt, C. M., Grant, M., Ko, C. Y., Wendel, C., \& Krouse, R. S. Demographic and Clinical Factors Related to Ostomy Complications and Quality of Life in Veterans With an Ostomy. Journal of Wound, Ostomy and Continence Nursing. September/October 2008 2008;35 (5):493-503.

10. Bekkers M, Van Knippenberg, F., Van Den Borne, H., \& Van BergeHenegouwen, G. Psychosocial adaptation to stoma surgery: A review. Journal of Behavioral Medicine. 1995;18(1):1-31.

11. Simmons K, Smith, J., Bobb, K., Liles, L. Adjustment to colostomy: stoma acceptance, stoma care self-efficacy, and interpersonal relationships. Journal of Advanced Nursing Dec 2007;60(6):627-635.

12. Wynd C, Schmidt, B., Schaefer, M. Two quantitative approaches for estimating content validity. Western Journal of Nursing Research 2003;25(5):508- 518.

13. DeVellis R. Scale Development: Theory and Applications. Vol 26. Thousand Oaks: Sage Publications; 2003.

14. Pittman J, Bakas, T. Measurement and Instrument Design. Journal Wound Ostomy Continence Nursing. 2010;37(6):603-607.

15. Lynn M. Determination and quantification of content validity. Nursing Research. 1986;35(6):382-386.

16. Sacks D. Content validity study for a survey to measure faculty attitudes towrds research and teaching at a doctoral/research extensive university. College of Education, Criminal Justice, and Human Services, University of Cincinnati, Cincinnati, Ohio.

17. Bekkers M, Van Knippenberg, F., Van Den Borne, H., \& Van BergeHenegouwen, G. Prospective evaluation of psychosocial adaption to stoma surgery: The role of self-efficacy. Psychosomatic Medicine. March/April 1996 1996;58(2):183-191.

18. Simmons K, Smith, J., Wroe, A., Rimmer-Gray, M., Ilett, H., Tyte, S. The OAI-23 in practice: 2366. Journal of Wound Ostomy Continence Nursing. 2008;35(3, Supplement):S50.

19. Simmons K, Smith, J., Maekawa, A. Development and psychometric evaluation of th Ostomy Adjustment Inventory-23. Journal Wound Ostomy Continence Nursing. 2009;36(1):69-76.

20. Polit D, Beck, C. The content validity index: Are you sure you know what's being reported? Critique and Recommendations. Res Nurs Health. 2006;29:489-497.

21. Waltz C, Strickland, O., Lenz, E. Measurement in nursing and health research. 3rd ed. New York: Springer Publishing Company; 2005.

22. Landis JR, \& Koch, G. G. The measurement of observer agreement for caategorical data. Biometrics. 1977;53:159-174. 
23. Polit D, Hungler, B. Nursing Research: Principles and Methods. 6th ed. Philadephia: Lippincott; 1999.

24. Bass E, Del Pino A., Tan, A., Pearl, R., Orsay, C., \& Abcarian, H. Does preoperative stomal marking and education by the enterostomal therapist affect outcome? Dis Colon Rectum. April 1997; Online November 2005 1997;40(4):440-442.

25. Gulbiniene J, Markelis, R., Tamelis, A., Saladzinskas, Z. The impact of preoperative stoma siting and stoma care education on patient's quality of life. Medicina. 2004;41(1):1045-1053.

26. Goldberg M, Aukett, L., Carmel, J., Fellows, J., Folkedahl, B., Pittman, J. Management of the patient with a fecal ostomy: Best practice guideline for clinicians. Mount Laurel, NJ: Wound, Ostomy and Continence Society; 2010.

27. American Society of Colon and Rectal Surgeons Committee Members, Wound Ostomy and Continence Nurses Society Committee Members. ASCRS and WOCN joint position statement on the value of preoperative stoma marking for patients undergoing fecal ostomy surgey. Journal of Wound Ostomy Continence Nursing. 2007;34(6):627-628.

28. McCann E. A content-validated tool to effectively document peristoma skin lesions. OstomyWound Management. 2010;October.

29. Kalashnikova I, Achkasov,S., Fadeeva, S., Vorobiev, G. The development and use of algorithms for diagnosing and choosing treatment of ostomy complications: Results of a prospective evaluation. Ostomy Wound Manage. 2011;57(1).

30. Fawcett J. Contemporary Nursing Knowledge: Analysis and evaluation of nursing models and theories. Second ed. Danvers, MA: F.A. Davis Company; 2005.

31. Beitz J, Gerlach, M., Ginsburg, P., Ho, M., McCann, E., Schafer, V., Scott, V., Stallings, B., \& Turnbull, G. Content validation of a standardized algorithm for ostomy care. Ostomy Wound Manage. 2010;56(10):22-38. 
Figure 1: Pittman Ostomy Complication Conceptual Model

\section{Antecedents (IV)}

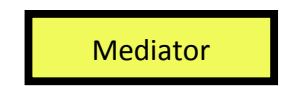

\section{Demographic Risk Factors:}

Age

Sex

Income

Education

Employment

Partner status

Environmental Risk Factors:

(Intrinsic):

Type of effluent

Stoma/abd characteristics

Nutritional status (Albumin, NPO)

BMI

Smoking status

Diagnosis

Ostomy Type

Timing of surgery

Comorbidities

Clinical Risk Factors:

(Extrinsic)

Pre-operative Education

Postoperative Education

Stomal Care Proficiency

Stoma site marking

Activities of Daily Living (ADL)
Outcomes (DV)
Ostomy Complications:

Leakage

Peristomal Irritant Dermatitis

Pain

Bleeding

Stomal necrosis

Stomal stenosis

Retraction

Mucocutaneous separation

Hyperplasia

CJoyce Pittman, 2011. Reprinted with permission. 
Table 1: Data Collection Timeline and Sources:

\begin{tabular}{|l|c|c|l|}
\hline Variables & Baseline & Follow-Up & Data Source \\
\hline $\begin{array}{l}\text { Patient survey (age, gender, education, } \\
\text { occupation, income, smoking, } \\
\text { comorbidities, ostomy education } \\
\text { provided by WOC nurse, ADL status) }\end{array}$ & $\mathrm{X}$ & & Self-report \\
\hline $\begin{array}{l}\text { Ostomy Complication Severity Index } \\
\text { (leakage, peristomal irritant dermatitis, } \\
\text { pain, bleeding, stomal necrosis, stomal } \\
\text { stenosis, retraction, mucocutaneous } \\
\text { separation, hyperplasia) }\end{array}$ & & $\mathrm{X}$ & $\begin{array}{l}\text { WOC nurse observation } \\
\text { Self-report }\end{array}$ \\
\hline $\begin{array}{l}\text { Ostomy risk factors (diagnosis, timing } \\
\text { of surgery, ostomy type, type of } \\
\text { effluent, stoma/abd characterisitics, } \\
\text { stoma-care proficiency, stoma site } \\
\text { marking, NPO status, BMI) }\end{array}$ & $\mathrm{X}$ & & $\begin{array}{l}\text { Medical record review } \\
\text { Self report } \\
\text { WOC nurse observation }\end{array}$ \\
\hline \begin{tabular}{l} 
Stoma Care Self-Efficacy Scale \\
\hline
\end{tabular} & $\mathrm{X}$ & $\mathrm{X}$ & Self report \\
\hline $\begin{array}{l}\text { Ostomy Adjustment Inventory-23 } \\
\text { Salf }\end{array}$ & & $\mathrm{X}$ & Self report \\
\hline
\end{tabular}


Table 2: Ostomy Complication Severity Index: Panel of Experts Mean Ratings

\begin{tabular}{|c|c|c|c|c|}
\hline \multirow[t]{2}{*}{$\underline{\text { OCSI }}$} & \multicolumn{4}{|c|}{ Mean (SD) } \\
\hline & $\begin{array}{l}\text { Relevance of item } \\
\text { 1. Item is NOT } \\
\text { relevant } \\
\text { 2. Item needs MAJOR } \\
\text { revision to be relevant } \\
\text { 3. Item needs MINOR } \\
\text { revision to be relevant } \\
\text { 4. Item IS relevant }\end{array}$ & $\begin{array}{l}\text { Clarity of item } \\
\text { 1. Item is NOT clear } \\
\text { 2. Item needs MAJOR } \\
\text { revision to be clear } \\
\text { 3. Item needs MINOR } \\
\text { revision to be clear. } \\
\text { 4. Item IS clear }\end{array}$ & $\begin{array}{l}\frac{\text { Comprehensiveness }}{\text { of item }} \\
\text { 1. Item should be } \\
\text { deleted. } \\
\text { 2. Item should be } \\
\text { retained. }\end{array}$ & $\begin{array}{l}\begin{array}{c}\text { Appropriateness of } \\
\text { numeric rating scale for } \\
\text { each item }\end{array} \\
\text { 1. Rating scale is } \\
\text { NOT appropriate. } \\
\text { 2. Rating scale needs } \\
\text { MAJOR revision to } \\
\text { be appropriate. } \\
\text { 3. Rating scale needs } \\
\text { MINOR revision to } \\
\text { be appropriate. } \\
\text { 4. Rating scale is } \\
\text { appropriate. }\end{array}$ \\
\hline Leakage & $3.6(0.97)$ & $3.2(1.23)$ & $1.9(0.32)$ & $3.4(0.97)$ \\
\hline $\begin{array}{l}\text { Peristomal irritant } \\
\text { dermatitis }\end{array}$ & $4.0 \quad(0)$ & $3.9(0.33)$ & $2.0 \quad(0)$ & $3.3(0.95)$ \\
\hline Pain & $3.3(0.95)$ & $3.0(1.15)$ & $1.9(0.32)$ & $3.2(1.03)$ \\
\hline Bleeding & $3.0(1.15)$ & $2.4(1.13)$ & $1.8(0.42)$ & $2.5(1.01)$ \\
\hline Stomal necrosis & $3.8(0.63)$ & $3.9(0.33)$ & $2.0 \quad(0)$ & $3.5(0.71)$ \\
\hline Stomal stenosis & $3.8(0.63)$ & $3.3(1.00)$ & $1.9(0.32)$ & $3.0(1.12)$ \\
\hline Retraction & $3.8(0.63)$ & $3.4(1.13)$ & $1.9(0.32)$ & $3.7(0.71)$ \\
\hline $\begin{array}{l}\text { Mucocutaneous } \\
\text { separation }\end{array}$ & $3.8(0.63)$ & $3.6(0.73)$ & $2.0 \quad(0)$ & $3.4(0.97)$ \\
\hline Hyperplasia & $3.6(0.97)$ & $3.8(0.67)$ & $2.0 \quad(0)$ & $3.7(0.67)$ \\
\hline Total (mean) & 3.6 & 3.4 & 1.9 & 3.3 \\
\hline
\end{tabular}


Table 3: Ostomy Complication Severity Index: Item and Total CVI Scores

\begin{tabular}{|l|c|c|c|}
\hline & \multicolumn{2}{|c|}{ Rated: } & \\
\hline OCSI & $\mathbf{1}$ or $\mathbf{2}$ & $\mathbf{3}$ or $\mathbf{4}$ & Item CVI \\
\hline Leakage & 1 & 9 & .90 \\
\hline Peristomal irritation & 0 & 10 & 1.00 \\
\hline Pain & 1 & 9 & .90 \\
\hline Bleeding & 2 & 8 & .88 \\
\hline Stoma necrosis & 1 & 9 & .90 \\
\hline Stoma stenosis & 1 & 9 & .90 \\
\hline Retraction & 1 & 9 & .90 \\
\hline $\begin{array}{l}\text { Mucocutaneous } \\
\text { separation }\end{array}$ & 1 & 9 & .90 \\
\hline Hypergranulation & 1 & 9 & .90 \\
\hline Total CVI & & & .91 \\
\hline
\end{tabular}

Table 4: Ostomy Complication Severity Index: Inter-rater reliability analysis $(n=6)$

\begin{tabular}{|l|c|c|}
\hline OCSI Item & \% Agreement & Kappa \\
\hline Leakage & $100 \%$ & 1.0 \\
\hline Peristomal irritant dermatitis & $100 \%$ & 1.0 \\
\hline Pain & $75 \%$ & 0.7 \\
\hline Bleeding & $100 \%$ & 1.0 \\
\hline Stomal necrosis & $100 \%$ & 1.0 \\
\hline Stomal stenosis & $100 \%$ & 1.0 \\
\hline Retraction & $100 \%$ & 1.0 \\
\hline Mucocutaneous separation & $100 \%$ & 1.0 \\
\hline Hyperplasia & $100 \%$ & 1.0 \\
\hline Total OCSI score & & $(p)$ \\
Pearson's Correlation & & $0.999(\leq 0.001)$ \\
Intra-class Correlation & & $0.991(\leq 0.001)$ \\
\hline
\end{tabular}


Table 5: Correlations among risk factors and ostomy complications (OCSI items)

\begin{tabular}{|c|c|c|c|c|c|c|c|c|c|c|}
\hline Variables & Leakage & $\begin{array}{l}\text { Peri-stomal } \\
\text { dermatitis }\end{array}$ & Pain & $\begin{array}{l}\text { Bleed- } \\
\text { ing }\end{array}$ & $\begin{array}{l}\text { Stomal } \\
\text { Necrosis }\end{array}$ & $\begin{array}{l}\text { Stomal } \\
\text { Stenosis }\end{array}$ & $\begin{array}{l}\text { Retrac- } \\
\text { tion }\end{array}$ & $\begin{array}{l}\text { MC } \\
\text { Sep }\end{array}$ & $\begin{array}{l}\text { Hyper } \\
\text { Plasia }\end{array}$ & $\begin{array}{l}\text { Total } \\
\text { score }\end{array}$ \\
\hline Gender & $.32 *$ & .198 & $.27^{*}$ & .25 & .14 & .09 & .11 & .03 & -.21 & $.32 *$ \\
\hline Age & -.15 & -.08 & -.01 & .03 & -.15 & -.03 & -.01 & .04 & .20 & -.06 \\
\hline Diagnosis & .05 & -.05 & -.09 & -.03 & -.01 & .17 & -.09 & .02 & .07 & -.03 \\
\hline Timing of surgery & -.16 & -.18 & -.12 & .04 & -.10 & .02 & .14 & .13 & .15 & -.07 \\
\hline Ostomy Type & $.31 *$ & $.26 *$ & .20 & -.07 & .11 & -.01 & -.16 & .06 & -.09 & .19 \\
\hline Type of Effluent & -.03 & .03 & -.05 & -.08 & .12 & .05 & -.08 & -.12 & .07 & -.06 \\
\hline $\begin{array}{l}\text { Stoma/abd } \\
\text { characteristics }\end{array}$ & .22 & .11 & $.30 *$ & $.28 *$ & $.28 *$ & .05 & $.57 * *$ & $.30 *$ & -.10 & $.43 * *$ \\
\hline Stoma care proficiency & .02 & -.15 & .01 & .05 & .20 & -.03 & .09 & .14 & .04 & .03 \\
\hline ADL function & -.07 & -.20 & $-.32 *$ & $-.25 *$ & .17 & $.29 *$ & -.11 & -.14 & .08 & -.23 \\
\hline $\begin{array}{l}\text { Pre-operative education by } \\
\text { WOC nurse }\end{array}$ & -.13 & -.12 & -.13 & .01 & -.17 & -.10 & .10 & .15 & .02 & -.05 \\
\hline $\begin{array}{l}\text { Stoma site marked by } \\
\text { WOC nurse }\end{array}$ & -.02 & -.12 & -.02 & .03 & -.13 & .13 & $.32 * *$ & $.30 *$ & .07 & .11 \\
\hline NPO status & -.21 & -.22 & -.11 & $-.35 * *$ & -.08 & -.04 & -.02 & -.08 & .10 & $-.25 *$ \\
\hline BMI (Spearman r) & $.42 * *$ & $.29 * *$ & .20 & .22 & .17 & .05 & .25 & .22 & .13 & $.36 * *$ \\
\hline BMI2 (continuous) & $.36 * *$ & .11 & .13 & .17 & .14 & .03 & $.28 *$ & $.26 *$ & -.10 & $.32 *$ \\
\hline Smoking status & -.04 & .03 & -.01 & -.12 & -.11 & -.09 & -.22 & -.01 & .18 & -.09 \\
\hline $\begin{array}{l}\text { Post-operative education } \\
\text { by WOC nurse }\end{array}$ & -.11 & -.09 & -.13 & -.03 & .15 & -.12 & -.05 & -.14 & -.06 & -.14 \\
\hline
\end{tabular}


Table 6: Univariate and Multivariate regression analyses of risk factors and ostomy complications (OCSI)

\begin{tabular}{|c|c|c|c|c|c|c|c|c|c|}
\hline \multirow[t]{2}{*}{ Outcome } & \multirow[t]{2}{*}{ Covariate } & \multicolumn{4}{|c|}{ Univariate } & \multicolumn{4}{|c|}{ Multivariate } \\
\hline & & $\mathbf{B}$ & SE & Beta & $p$ & $\mathbf{B}$ & SE & Beta & $p$ \\
\hline \multirow{14}{*}{$\begin{array}{l}\text { OCSI Total } \\
\text { score }\end{array}$} & Age & -.177 & .404 & -.057 & .663 & .948 & .476 & .302 & .053 \\
\hline & Diagnosis & -.107 & .490 & -.028 & .828 & 1.202 & .644 & .320 & .068 \\
\hline & Timing of surgery & -.160 & .319 & -.065 & .619 & -.856 & .528 & -.348 & .112 \\
\hline & Ostomy type & .487 & .331 & .188 & .147 & -.007 & .395 & -.003 & .985 \\
\hline & Type of effluent & -.341 & .811 & -.055 & .676 & .997 & .855 & .159 & .250 \\
\hline & Stoma/abd characteristics & 1.503 & .407 & .433 & .000 & 1.269 & .445 & .365 & .007 \\
\hline & Stoma care proficiency & .119 & .479 & .032 & .805 & -.256 & .507 & -.070 & .616 \\
\hline & ADL & -.796 & .439 & -.230 & .075 & -.819 & .420 & -.236 & .057 \\
\hline & $\begin{array}{l}\text { Pre-operative education by } \\
\text { WOC }\end{array}$ & -.136 & .329 & -.054 & .681 & -.196 & .377 & -.078 & .605 \\
\hline & Stoma site marked by WOC & .256 & .306 & .109 & .408 & .566 & .375 & .241 & .138 \\
\hline & NPO status & -.882 & .449 & -.248 & .054 & -.496 & .532 & -.139 & .356 \\
\hline & BMI & 1.375 & .370 & .435 & .000 & 1.412 & .427 & .441 & .002 \\
\hline & Smoking & -.322 & .447 & -.093 & .474 & .122 & .403 & .035 & .764 \\
\hline & $\begin{array}{l}\text { Post-operative education by } \\
\text { WOC }\end{array}$ & -.527 & .480 & -.143 & .277 & -.376 & .525 & -.102 & .478 \\
\hline
\end{tabular}


Table 7: Incidence and severity of ostomy complications at 30-60 days by study site

\begin{tabular}{|c|c|c|c|c|c|c|}
\hline Ostomy Complications & SITE 1 & SITE 2 & SITE 3 & TOTAL & & \\
\hline & $\begin{array}{l}n=18 \\
n(\%)\end{array}$ & $\begin{array}{l}n=42 \\
n(\%)\end{array}$ & $\begin{array}{l}n=10 \\
n(\%)\end{array}$ & $\begin{array}{l}\mathrm{n}=70 \\
\mathrm{n}(\%)\end{array}$ & $\begin{array}{l}\text { Chi } \\
\text { square }\end{array}$ & $p$ \\
\hline $\begin{array}{l}\text { Leakage } \\
\text { None } \\
1-2 \mathrm{x} / \mathrm{mo} \\
1-2 \mathrm{x} / \text { wk } \\
1-2 \mathrm{x} / \text { day }\end{array}$ & $\begin{array}{l}5(36) \\
3(21) \\
6(43) \\
0\end{array}$ & $\begin{array}{r}13(35) \\
9(24) \\
10(27) \\
5(14)\end{array}$ & $\begin{array}{l}7(64) \\
1(9) \\
1(9) \\
2(18)\end{array}$ & $\begin{array}{r}25(40) \\
13(21) \\
17(27) \\
7(11)\end{array}$ & 7.52 & .276 \\
\hline $\begin{array}{l}\text { Peristomal Irritant Dermatitis } \\
\text { None } \\
\text { Mild } \\
\text { Moderate } \\
\text { Severe }\end{array}$ & $\begin{array}{l}9(64) \\
2(14) \\
3(21) \\
0\end{array}$ & $\begin{array}{r}15(41) \\
12(32) \\
6(16) \\
4(11)\end{array}$ & $\begin{array}{l}7(64) \\
3(27) \\
1(9) \\
0\end{array}$ & $\begin{array}{c}31(50) \\
17(27) \\
10(16) \\
4(7)\end{array}$ & 6.15 & .407 \\
\hline $\begin{array}{l}\text { Stomal Pain } \\
\text { None } \\
1-3 \\
4-6 \\
7-10 \\
\text { Mean (SD) } \\
\end{array}$ & $\begin{array}{l}7(50) \\
3(21) \\
1(7) \\
3(21) \\
1.25(2.5)\end{array}$ & $\begin{array}{l}21(57) \\
8(22) \\
4(11) \\
4(11) \\
1.89(2.9)\end{array}$ & $\begin{array}{l}8(73) \\
3(27) \\
0 \\
0 \\
1.64(2.7)\end{array}$ & $\begin{array}{l}36(58) \\
14(23) \\
5(8) \\
7(11) \\
1.71(2.8)\end{array}$ & 4.48 & $\begin{array}{r}.612 \\
.794 \\
\end{array}$ \\
\hline $\begin{array}{l}\text { Stomal Bleeding } \\
\text { None } \\
\text { Superficial } \\
\text { Moderate } \\
\text { Severe } \\
\end{array}$ & $\begin{array}{l}8(57) \\
4(29) \\
1(7) \\
1(7)\end{array}$ & $\begin{array}{l}25(68) \\
12(32) \\
0 \\
0\end{array}$ & $\begin{array}{l}9(82) \\
1(9) \\
1(9) \\
0\end{array}$ & $\begin{array}{c}42(68) \\
17(27) \\
2(3) \\
1(2)\end{array}$ & 8.71 & .191 \\
\hline $\begin{array}{l}\text { Stomal Necrosis } \\
\text { None } \\
\text { Stoma Dusky } \\
\text { Stoma } 50 \% \text { black } \\
\text { Stoma }>50 \% \text { black } \\
\end{array}$ & $\begin{array}{l}15 \text { (100) } \\
0 \\
0 \\
0\end{array}$ & $\begin{array}{l}36(97) \\
1(3) \\
0 \\
0 \\
\end{array}$ & $\begin{array}{l}11(100) \\
0 \\
0 \\
0\end{array}$ & $\begin{array}{c}62(98) \\
1(2)\end{array}$ & 0.71 & .700 \\
\hline $\begin{array}{l}\text { Stomal Stenosis } \\
\text { None }\end{array}$ & $14(93)$ & $36(97)$ & $10(91)$ & $60(95)$ & 3.71 & .447 \\
\hline
\end{tabular}




\begin{tabular}{|c|c|c|c|c|c|c|}
\hline $\begin{array}{l}<5^{\text {th }} \text { digit diameter, no } \\
\text { discomfort } \\
<5^{\text {th }} \text { digit diameter, } \\
\text { occasional discomfort } \\
\text { Unable to insert } 5^{\text {th }} \text { digit, } \\
\text { no output }\end{array}$ & $\begin{array}{l}0 \\
1(7) \\
0\end{array}$ & $\begin{array}{l}1(3) \\
0 \\
0\end{array}$ & $\begin{array}{l}0 \\
1(9) \\
0\end{array}$ & $\begin{array}{l}1(2) \\
2(3) \\
0\end{array}$ & & \\
\hline $\begin{array}{l}\text { Stomal Retraction } \\
\text { Stoma above skin } \\
\text { Stoma skin level } \\
\text { Stoma below skin level } \\
\text { Stoma }>2 \mathrm{~cm} \text { below skin level } \\
\end{array}$ & $\begin{array}{l}6(40) \\
6(40) \\
3(20) \\
0\end{array}$ & $\begin{array}{l}27(73) \\
9(24) \\
1(3) \\
0 \\
\end{array}$ & $\begin{array}{l}6(55) \\
2(18) \\
2(18) \\
1(9) \\
\end{array}$ & $\begin{array}{c}39(62) \\
17(27) \\
6(10) \\
1(2) \\
\end{array}$ & 12.48 & .052 \\
\hline $\begin{array}{l}\text { Mucocutaneous Separation } \\
\text { None } \\
1-49 \% \\
50-74 \% \\
75-100 \% \\
\end{array}$ & $\begin{array}{c}11(73) \\
2(13) \\
1(7) \\
1(7) \\
\end{array}$ & $\begin{array}{l}35(95) \\
1(3) \\
0 \\
1(3) \\
\end{array}$ & $\begin{array}{l}9(82) \\
0 \\
0 \\
2(18) \\
\end{array}$ & $\begin{array}{l}55(87) \\
3(5) \\
1(2) \\
4(6) \\
\end{array}$ & 10.17 & . 118 \\
\hline $\begin{array}{l}\text { Hyperplasia } \\
\text { None } \\
1-49 \% \\
50-74 \% \\
75-100 \%\end{array}$ & $\begin{array}{l}13(87) \\
2(13) \\
0 \\
0\end{array}$ & $\begin{array}{l}36(97) \\
1(3) \\
0 \\
0 \\
\end{array}$ & $\begin{array}{l}11(100) \\
0 \\
0\end{array}$ & $\begin{array}{l}60(95) \\
3(5) \\
0 \\
0 \\
\end{array}$ & 3.33 & 190 \\
\hline $\begin{array}{l}\text { Ostomy Complications present } \\
\text { No } \\
\text { Yes }\end{array}$ & $\begin{array}{c}1(7) \\
13(93)\end{array}$ & $\begin{array}{r}6(16) \\
31(84)\end{array}$ & $\begin{array}{l}3(30) \\
8(73)\end{array}$ & $\begin{array}{l}10(16) \\
52(84)\end{array}$ & 1.85 & . 397 \\
\hline OCSI Total Score & $5(3.5)$ & 4 (3.5) & $3(3.8)$ & 4 (3.5) & & .546 \\
\hline
\end{tabular}

